\title{
A nálise comparativa dos dispositivos de saúde do trabalhador nas constituições estaduais brasileiras
}

\author{
Workers' health in Brazilian state constitutions: \\ a comparative analysis
}

Maria Helena Barros de Oliveira 1 Luiz Sérgi o Brandão de Oliveira 2 Fátima Sueli Neto Ribei ro 3 Luiz Carlos Fadel deVasconcellos 4

\footnotetext{
1 Centro de Estudos da Saúde do Trabalhador e Ecologia Humana, Escola Nacional de Saúde Pública, Fiocruz. Rua Leopoldo Bulhões 1480, Rio de Janeiro, RJ 21041-210, Brasil.

2 Delegacia Regional do Trabalho do Rio de Janeiro. Av. Presi dente Antônio Carlos 251/10o andar, Rio de Janeiro, RJ 20020-000, Brasil. 3 Universi dade do Estado do Rio de Janeiro. Rua São Francisco Xavier 524/12o andar, Rio de Janeiro, RJ 20550-013, Brasil. 4 Programa de Saúde do Trabalhador, Secretaria de Estado de Saúde do Rio de Janeiro. Rua México 128, sala 419, Rio de Janeiro, RJ 20031-142, Brasil.
}

Abstract This articlebriefly analyzes the legal measures related to workers' health in the various Brazilian state constitutions. It makes a qual itative and quantitative comparison of the different provisions based on the presence, weight, and relevance ascribed to the issue, using predefined attributes: statement of guidelines; production, control, and utilization of information; labor intervention; guarantee of rights. The analysi s showed legi slators' intent to allocate power to the Unified Health System in the field of workers' health so as to all ow for new practices in this area.

Key words Workers' Health; Legislation; State Constitution; Health Systems

Resumo O presente artigo trata de uma anál ise sumária dos dispositivos legais relacionados à área de Saúde do Trabal hador, encontrados nas Constitui ções dos Estados Brasilei ros. Compara, deforma qualitativa e quantitativa, os diversos dispositivos, segundo sua presença, abrangência e importância, mediante a adoção de cri téri os preestabel eci dos de análi se em quatro grupos de atributos: estabel ecimento de diretrizes/geração, control e e utilização de informações/intervenção sobre os ambientes de trabalho/garantia de di reitos de cidadania. A anál ise evidenciou a intenção do legi sl ador de conferir ao Sistema Ú ni co de Saú de atribui ções em Saúde do TrabaIhador, possibilitando a implementação de novas práticas.

Palavras-chave Saúdedo Trabalhador; Legislação; Constituição Estadual; Sistemas de Saúde 


\section{Introdução}

A área de Saúde do Trabalhador, por suas características estruturais e de inter-rel ação, alicerça-se numa dinâmica que envolve diversos atores sociais, especialmente do movimento organizado dos trabalhadores e das instituições que tratam das especificidades da questão.

O período que antecedeu o processo constituinte de 1986-1988, no contexto do Movimento pela Reforma Sanitária, foi marcado por uma intensa mobilização desses atores, cuja expressão maior foi a realização, em 1986, da I Conferência Nacional de Saúde do Trabalhador. Calcadas na necessidade inquestionável de transformação do setor, as teses e propostas formuladas em nível nacional apontavam para a redefinição da área e sua incorporação ao nascente Sistema Único de Saúde (SUS).

Levadas ao processo constituinte, a síntese dessas propostas foi traduzida na Constituição Federal de 1988, em seu capítulo da saúde, pela determinação ao Sistema Único de Saúde SUS da execução de ações de Saúde do TrabaIhador:

"Art. 200. Ao Sistema Ú nico de Saúde compete, além de outras atribui ções, nos termos da lei: (...)

II - executar as ações de vigilância sanitária eepidemiológica, bem como as de saúde do trabalhador" (Brasil, 1988).

Refletiu, desta forma, a intencionalidade da Assembléia Nacional Constituinte de redefinir essas questões, ao nível do Estado, remetendo às constituições estaduais e à legislação ordinária de saúde sua regulamentação.

Ao se adequarem ao preceito de Saúde do Trabalhador da Constituição Federal, as constituições estaduais de 1989, em sua maioria, embora tenham estabelecido seus dispositivos de forma diversa, conferiram ao SUS a capacidade de imprimir à área uma sustentação legal do processo de transformação de suas práticas.

A aproximação entre os caracteres da lei e da política dela decorrente, efetivamente implementada, leva a supor que, em especial, essas leis específicas possuíam (e possuem) uma capacidade de servir como real instrumento de mudança.

A correlação de forças presentes no momento constituinte, propiciando a construção das novas legislações de Saúde do Trabalhador, contidas em diversas constituições estaduais, conferiu-Ihes um papel instigante no sentido da transformação, levando a crer que a incorporação das ações de Saúde do Trabalhador no SUS pode contribuir para a superação do mo- delo político-institucional existente na área (Vasconcellos, 1994).

A comparação das constituições estaduais, objeto deste trabal ho, pretende contribuir para uma discussão que carece de reflexões teóricas sobre o papel do SUS na área de Saúde do Trabalhador, dentro da nova configuração legal.

Questões como a capacidade de implementar políticas públicas, seus desdobramentos no campo das práticas e, no seu ponto mais crítico, o conflito de atribuições, na esfera das instituições públicas, remetem à necessidade de aprofundamento da análise dos instrumentos normativos. Oliveira (1994:218) realça o debate ao assinalar: "o conflito contemporâneo travado entre os setores do trabal ho eda saúdeé, assim, sob determinado aspecto, uma batal ha no campo do direito, pelo reconheci mento de fato, do setor saúde intervir ampla eativamentesobre os ambientes de trabal ho".

A concepção do Sistema Único de Saúde, ao adotar os princípios de unicidade e descentralização, desconcentrando poder e viabilizando instâncias de controle social, expressou a inadequação do modelo anterior da saúde, no Brasil. Da mesma forma, a área de Saúde do Trabalhador, no seu contingente legislativo, simultaneamente à reforma da área de saúde, sinalizou para a necessidade de ruptura com o modelo preestabelecido ao SUS.

As características da área, no modelo anterior ao SUS, foram analisadas e discutidas por diversos autores (Mendes, 1986; Tambellini, 1986; Oliveira \& Vasconcellos, 1992; VasconcelIos, 1994; Oliveira, 1994; Dias, 1995) e têm como pontos críticos, e comprometedores, a fragmentação institucional, a marginalidade da área no campo das políticas públicas, o alijamento dos trabal hadores dos processos de intervenção e, entre outros, a falácia das informações.

\section{O processo constituinte estadual}

A diversidade da forma como está expressa a questão da Saúde do Trabal hador nos textos constitucionais de cada estado brasileiro faz supor que, no momento da constituinte estadual, havia uma dada conjuntura política favorável ou não a sua incorporação na lei, gerando embates entre setores mais sintonizados com a necessidade de transformação da área, e outros, mais conservadores ou, ainda, menos sensibilizados com a reforma.

Conteúdo e forma da letra da lei, nas constituições estaduais, e diferenças marcantes entre elas levam, também, a supor uma dificulda- 
de de percepção, por parte dos constituintes estaduais, do alcance e abrangência da questão. O fato de que o processo de regulamentação da Constituição Federal, no que diz respeito ao capítulo da saúde, ou seja, a Lei Orgânica da Saúde - LOS -, tenha ocorrido posteriormente (1990) à promulgação das constituições estaduais (1989), certamente contribuiu para reforçar esta suposição.

É muito provável que os dispositivos referentes à Saúde do Trabal hador na LOS, caso esta tivesse sido promulgada antes, pudessem ter servido aos parlamentares como parâmetro de discussão à época da constituinte estadual, uma vez que foi naquela, em seu artigo sexto, parágrafo terceiro (MS, 1990), que se definiu a área de Saúde do Trabalhador do ponto de vista do seu conceito e de sua abrangência de ações.

Recuperar o processo de discussão travado nas constituintes estaduais, para compreender por que al gumas constituições sequer mencionam a questão de Saúde do Trabalhador (algumas o fazem de forma tímida e outras de forma mais incisiva) é tarefa extremamente difícil, devido à parcialidade dos registros documentais. Acrescente-se o fato de não se ter registrado todo o movimento de articulação de forças políticas em decorrência de lobbies e assessorias técnicas no momento constituinte. Há, ainda, que se destacar a dificuldade de acesso à documentação existente sobre o processo constituinte, comprovada por tentativas frustradas dos autores, neste sentido, em algumas Assembléias Legislativas Estaduais.

É evidente que uma série de fatores levou os constituintes de alguns estados a se omitirem quanto à Saúde do Trabalhador, deixando de atender, inclusive, a diretriz bem assinalada pela Constituição Federal no sentido da incorporação da área pelo SUS.

Certamente, um desses fatores, que já aflorara no processo constituinte federal, foi a tentativa de manter a hegemonia da intervenção sobre os processos de produção, quanto à segurança e à saúde, na esfera do setor Trabalho. Tratava-se, portanto, de preservar a área de Saúde do Trabalhador fora do campo de abrangência do setor Saúde. A sujeição da relação capital/trabal ho a um novo campo de intervenção do setor social poderia expor e tornar mais vulneráveis os processos produtivos causadores de danos à saúde, na medida de sua abordagem diferenciada, sob os pressupostos de controle sanitário, emergente de um projeto societário participativo, como foi o caso do Movimento pela Reforma Sanitária.

Cabe ressaltar que, por parte do movimento sindical, salvo exceções, a luta pela Saúde do
Trabalhador não era à época, como ainda não é, uma questão que ocupasse lugar destacado em seu rol de preocupações. É possível, portanto, que esse fato tenha sido responsável por uma pressão social insuficientemente capaz de tornar a correlação de forças mais favorável à questão.

Em função das dificuldades em se resgatar a totalidade das motivações, objetivas e subjetivas, dos parlamentares, no momento legislador, é crível que muito da omissão, timidez ou ousadia do legislador foi fruto da correlação de forças estabelecida no processo constituinte, cuja expressão retrata a predominância de uma ou outra vertente partidária nas comissões de saúde.

\section{Analisando as constituições estaduais}

Devido às dificuldades antes descritas, no que tange ao levantamento de informações capazes de retratar a dinâmica do processo optouse por trabalhar com o produto final das discussões, ou seja, a própria Constituição Estadual no seu capítulo da saúde. Pela forma como estão ou não colocadas as questões de Saúde do Trabalhador na lei, evidenciaram-se os pontos que, abaixo discriminados, consignam o escopo deste trabalho:

- a delimitação da área de abrangência das questões de Saúde do Trabalhador, a partir da análise do capítulo da saúde nas constituições estaduais;

- a identificação dos estados em que a legislação foi considerada mais avançada por conter um maior número de atributos em relação à área, como também pela qualidade das citações referidas e

- a elaboração de uma análise comparativa entre os estados, possibilitando sua utilização como instrumento de intervenção na área e como "modelo" para discussões posteriores.

\section{Metodologia empregada}

Para analisar as constituições, buscou-se, inicialmente, definir o que pode ser considerado como "essência da área". Para tanto, foram utilizados os preceitos definidos na LOS, aos quais se agregou o próprio entendimento dos autores, fundamentado em sua experiência acumulada na questão.

Especificamente, foi considerado como essência da área um conjunto de atributos capazes de conferir ao SUS uma ampla gama de atuação que desse conta da sua complexidade. 
Partindo da idéia principal, contida em cada um dos atributos, foi possível reuni-los em quatro grupos, conforme está demonstrado na Tabela 1.

Os atributos, em número de vinte, foram agrupados em função da similaridade de seus objetivos e algumas características comuns, tais como a sua abrangência e a provável conseqüência no caso da sua implementação.

Cada um dos atributos foi definido e agrupado após o exame detalhado de todos os dispositivos constitucionais de cada um dos estados. É importante assinalar que o tipo de dispositivo - artigo, parágrafo, inciso e alínea -, embora demarcando a importância conferida pelos constituintes, segundo o tema a que se refere, demonstra a intenção de se conferir um grau hierárquico de importância ao dispositivo; na verdade, do ponto de vista da sua aplicabilidade, seja qual for o seu tipo, a força da lei é igual em todos.

Assim, todos os dispositivos - artigo, parágrafo, inciso e alínea - foram considerados de forma igualitária e mesmo peso de valoração, independentemente do tipo.
Uma primeira aproximação quantitativa foi efetuada, correlacionando-se o número total de dispositivos de Saúde do Trabalhador ao número total de dispositivos no capítulo da saúde de cada uma das constituições estaduais, conforme demonstra a Figura 1.

Após essa etapa, cada um dos dispositivos referentes à Saúde do Trabalhador, registrados na Figura 1, foi avaliado qualitativamente, sendo classificado como de citação direta ou indireta, segundo sua referência explícita ou não à essência da área, nos moldes do considerado no quadro de atributos (Tabela 1 ).

Nos dispositivos em que houve dificuldade para diferenciar-se a citação, se direta ou indireta, tentou-se recuperar a informação mais fidedigna em outros dispositivos. Se, ainda assim, houve persistência da dúvida, considerou-se o dispositivo como sendo de citação indireta.

A forma como esses dispositivos foram expressos, direta ou indiretamente, delineou perfis de competência legal diferentes e conferiu atributos diversos aos Estados da federação, com uma maior ou menor amplitude.

Tabela 1

Essência da área de Saúde do Trabalhador, segundo atributos preestabelecidos.

\begin{tabular}{l|l}
\hline Atributos & Grupos \\
\hline $\begin{array}{l}\text { 1 - Formulação de políticas } \\
\text { - Criação de sistemas, programas } \\
\text { e planos de saúde do trabalhador } \\
3 \text { - Execução das ações de Saúde do Trabalhador } \\
4 \text { - Normatização }\end{array}$ & I - Estabelecimento de diretrizes para a área \\
\hline 5 - Notificação compulsória & \\
6 - Organização e registro de informações & II - Geração, controle e utilização de informações \\
7 - Estudo e pesquisa & \\
\hline 8 - Controle de condições, dos processos & \\
e organização dos ambientes de trabalho & \\
9 - Fiscalização/Inspeção & III - Intervenção sobre os ambientes de trabalho \\
10 - Eliminação de riscos & \\
11 - Prevenção & \\
12 - Intervenção do local de trabalho & \\
13 - Vigilância sanitária & \\
\hline 14 - Assistência/Recuperação & \\
15 - Acesso do trabalhador às informações & \\
16 - Participação sindical & \\
17 - Recusa ao trabalho ambientes de risco & \\
18 - Participação dos trabalhadores e entidades & sindicais na gestão dos serviços \\
19 - Requerer interdição ambiente de trabalho & \\
20 - Apuração de responsabilidade & \\
\hline
\end{tabular}


Tendo em vista que as citações diretas fazem uma referência explícita à essência da área, e acreditando que o legislador, ao enunciar com objetividade o dispositivo, teve a intenção de facilitar sua aplicabilidade, optou-se por considerar, exclusivamente, os dispositivos definidos como de citação direta.

Cabe salientar que um determinado dispositivo pode conter um ou mais atributos referenciados à essência da área e, igualmente, podem-se encontrar vários dispositivos na mesma lei estadual, todos referenciados ao mesmo atributo. Daí não haver, necessariamente, concordância numérica entre dispositivos e atributos.

Para efeito da análise pretendida neste trabalho, finalmente, considerou-se como ponto essencial de síntese o atributo, segundo a classificação da Tabela 1, como o parâmetro principal de avaliação.

\section{Por dentro das constituições estaduais}

A análise das constituições estaduais mostra a peculiaridade, que merece destaque, de que em alguns estados brasileiros a Saúde do Trabalhador não foi incluída como preocupação dos legisladores, não sendo sequer mencionada em seu capítulo da saúde, conforme foi demonstrado na Figura 1. Este fato ocorreu nos Estados de Alagoas, Paraíba, Paraná, Rio Grande do Norte e Santa Catarina, representando $19,23 \%$ no universo dos 26 Estados analisados.

Após o levantamento de todos os dispositivos de Saúde do Trabal hador, mencionados di- reta ou indiretamente nos 21 estados restantes, cujo total foi registrado na Figura 1, as citações consideradas como diretas foram classificadas, resultando nos diversos atributos dispostos na Tabela 2.

Como pode ser visto na Tabela 2, a idéia de criação da área no Sistema Único de Saúde, caracterizada pelos atributos do Grupo I - formulação de políticas, criação de sistemas, programas e planos de Saúde do Trabal hador, execução das ações de Saúde do Trabalhador e normatização (quatro atributos) -, é significativa, presente em 13 estados, o que representa $61,9 \%$ do universo analisado (21 estados).

Demarca esse dado a resultante histórica de todo um movimento de organização dos trabalhadores, ocorrido a partir do final da década de 70, com reflexos, à época, na criação de Programas de Saúde do Trabal hador em alguns estados. Observa-se, assim, de forma expressiva na legislação, a determinação do estabelecimento de uma política definida, impondo uma necessidade de articulação das ações de Saúde do Trabal hador no SUS (Dias, 1995).

Cabe destacar, porém, que, dos 13 estados que se referem ao estabelecimento de diretrizes para a área, em cinco deles (Goiás, Minas Gerais, M ato Grosso do Sul, Roraima eTocantins), essas diretrizes não são especificadas através de outros dispositivos, deixando-se de definir quais as ações a serem executadas. À exceção do Mato Grosso do Sul, reproduziu-se literalmente o disposto no artigo 200 da Constituição Federal - execução das ações deSaúde do Trabal hador (atributo de no 3).

Figura 1

Dispositivos de saúde e dispositivos de saúde do trabalhador nas constituições estaduais.

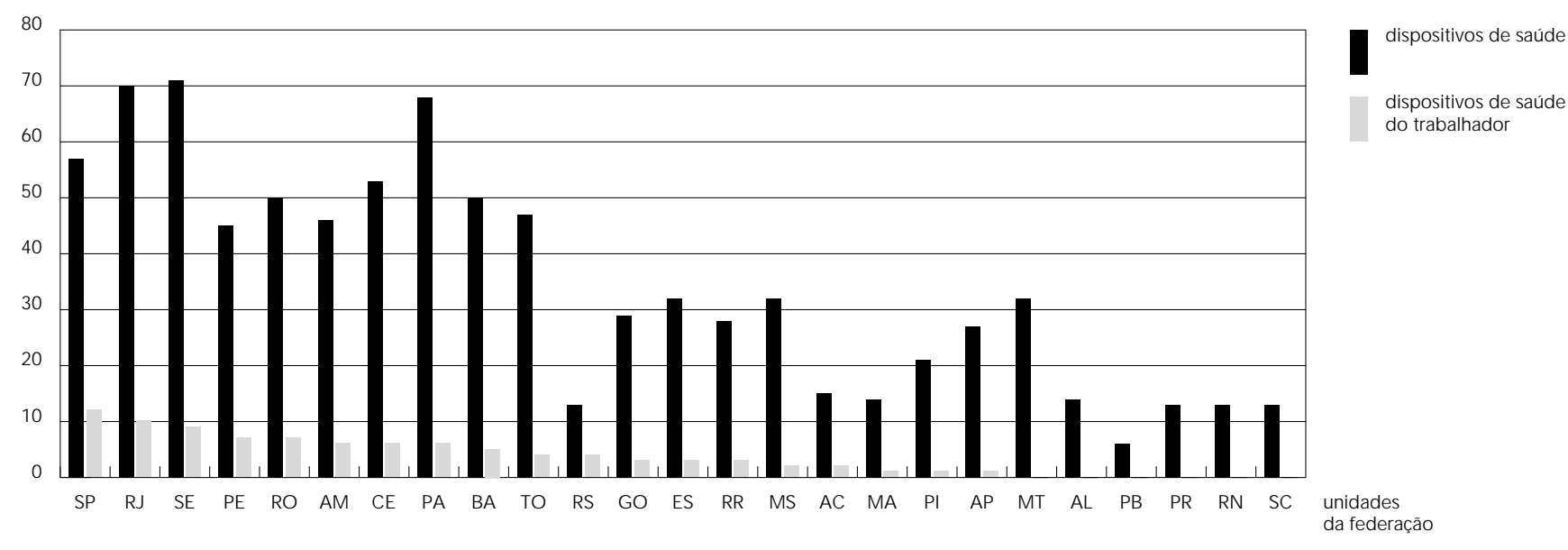


Tabela 2

Atributos de saúde do trabalhador, por grupo temático, nas constituições estaduais brasileiras.

\begin{tabular}{|c|c|c|c|c|c|c|c|c|c|c|c|c|c|c|c|c|c|c|c|c|c|c|}
\hline \multirow[b]{2}{*}{$\begin{array}{l}\text { Atributos de Saúde } \\
\text { do Trabalhador }\end{array}$} & \multicolumn{22}{|c|}{ Unidades da Federação } \\
\hline & $A C$ & $A M$ & AP & BA & CE & ES & GO & MA & MG & MS & MT & PA & PE & PI & RJ & RO & $\mathrm{RR}$ & RS & SE & SP & TO & $\begin{array}{l}\text { Total } \\
\text { atrib. }\end{array}$ \\
\hline Grupo I & & & & & & & & & & & & & & & & & & & & & & \\
\hline 1) Formulação de políticas & & & & & & & & & & - & & & & & & & & & & & & 1 \\
\hline $\begin{array}{l}\text { 2) Criação de sistemas, } \\
\text { programas e planos de ST }\end{array}$ & & • & & & & - & & & & - & & & & & & - & & & & & & 4 \\
\hline 3) Execução das ações de ST & & & & • & & & • & & • & & & & & • & $\cdot$ & & $\cdot$ & & • & • & • & 9 \\
\hline 4) N ormatização & & - & & $\cdot$ & & & & & & & & & & & $\cdot$ & & & & & & & 3 \\
\hline Grupo II & & & & & & & & & & & & & & & & & & & & & & \\
\hline 5) Notificação compulsória & & & & & & & & & & & & & & & - & & & & & & & 1 \\
\hline $\begin{array}{l}\text { 6) O rganização e registro } \\
\text { de informações }\end{array}$ & & & & & & & & & & & - & & & & & & & & & & & 1 \\
\hline 7) Estudo e pesquisa & & & & & & & & & & & & & & & $\cdot$ & & & & & & & 1 \\
\hline $\begin{array}{l}\text { Grupo III } \\
\text { 8) Controle das condições, } \\
\text { processos e organização } \\
\text { dos ambientes de trabalho } \\
\text { na gestão dos serviços }\end{array}$ & & - & - & - & - & - & & & & & & - & • & & & & & - & & - & & 9 \\
\hline 9) Fiscalização/Inspeção & & • & & $\cdot$ & • & • & & - & & & & • & $\cdot$ & • & • & & & $\cdot$ & & & & 10 \\
\hline 10) Eliminação de riscos & & • & & & • & • & & & & & & • & $\cdot$ & & $\cdot$ & • & & & • & & & 8 \\
\hline 11) Prevenção & & • & & & & & & & & & & & $\cdot$ & & $\cdot$ & & & & & - & & 4 \\
\hline $\begin{array}{l}\text { 12) Intervenção no local } \\
\text { de trabalho }\end{array}$ & & & & & & & & & & & & & & & • & & & & & & & 1 \\
\hline 13) Vigilância sanitária & & & & & & & & & & & & & - & & & - & & & & & & 2 \\
\hline Grupo IV & & & & & & & & & & & & & & & & & & & & & & \\
\hline 14) Assistência/Recuperação & $\cdot$ & • & & $\cdot$ & & & & & & & & & $\cdot$ & & $\cdot$ & & & & & & & 5 \\
\hline $\begin{array}{l}\text { 15) Acesso do trabalhador } \\
\text { às informações }\end{array}$ & & - & & - & & & & & & & & - & $\cdot$ & & $\cdot$ & $\cdot$ & & & • & $\cdot$ & & 8 \\
\hline 16) Participação sindical & & • & & & & & & & & & & • & $\cdot$ & & • & & & & & • & & 5 \\
\hline $\begin{array}{l}\text { 17) Recusa ao trabalho em } \\
\text { ambientes de risco }\end{array}$ & & & & • & & & & & & & & & & & $\cdot$ & - & & & • & • & & 5 \\
\hline $\begin{array}{l}\text { 18) Participação dos } \\
\text { trabalhadores e entidades }\end{array}$ & & & & & & & & & & & & & - & & & - & & & - & & & 3 \\
\hline $\begin{array}{l}\text { 19) Requerer interdição } \\
\text { do ambiente trabalho }\end{array}$ & & & & & & & & & & & & & & & & & & & & • & & 1 \\
\hline $\begin{array}{l}\text { 20) Apuração de } \\
\text { responsabilidade }\end{array}$ & & & & & • & & & & & & & & & & & & & & & & & 1 \\
\hline Total de atributos por estado & 1 & 9 & 1 & 7 & 4 & 4 & 1 & 1 & 1 & 2 & 1 & 5 & 9 & 2 & 12 & 6 & 1 & 2 & 5 & 7 & 1 & 82 \\
\hline
\end{tabular}


Ao não se definirem, de forma explícita, quais as ações a serem executadas, levando-se em conta que a constituição estadual tende a lapidar e esmiuçar o texto constitucional maior, demonstra-se, por um lado, a escassez das discussões, se é que houve, relacionadas à questão de Saúde do Trabalhador e, por outro, a expressão tímida na forma de se referir à área, provavelmente em face da correlação de forças presentes no momento constituinte.

O atributo de no 1 - formulação de política indica, de forma preciosa, que a lei pode ser um fator determinante de uma política e, portanto, instrumento de transformação da realidade. Esse atributo, contudo, foi encontrado apenas na Constituição do Mato Grosso do Sul, representando $5 \%$ dos 21 estados analisados.

O Grupo II, que caracteriza a geração, controle e utilização de informações, e que é representado pelos atributos notificação compulsória; organização e registro de informações e estudo e pesquisa (três atributos), só está presente em dois estados, equivalendo a 9,5\% do total de estados.

Isto, sem dúvida, reflete o pouco valor atribuído à produção de informações para o crescimento da área, exceção feita aos Estados do Rio de Janeiro, que se refere à notificação compulsória e estudo e pesquisa, e do Mato Grosso, que aborda a questão da organização e registro das informações.

O Grupo III, que se refere ao direito de intervir sobre os ambientes de trabalho, e que é caracterizado pelos atributos de no 8 a 13 (seis atributos), foi encontrado em 14 estados, equivalendo a $66,7 \%$ do universo analisado.

Dentro deste grupo, os atributos mais citados são os de no 8, 9 e 10 - controle das condições, processos e organização dos ambientes de trabalho; fiscalização/ inspeção e eliminação de riscos. Este fato possui uma relevância marcante ao resgatar para o SUS e, portanto, para o setor Saúde, ações que estavam confinadas, há décadas, à esfera de competência do setor Trabal ho (Oliveira, 1994). Estas atribuições, de caráter interventor, têm influenciado sobremaneira o setor Saúde no sentido de estabelecer novos paradigmas metodológicos de Vigilância em Saúde do Trabalhador (Machado \& Barcellos, 1993; MS, 1994; Ribeiro, 1994; Vasconcellos \& Ribeiro, no prelo).

Ainda dentro do mesmo grupo, a questão da prevenção (atributo de no 11) está manifesta nas constituições de apenas quatro estados (19\%), e a atribuição de intervenção, através da vigilância sanitária, em três deles (14,3\%).

$\mathrm{O}$ atributo de no 12 - intervenção no local de trabalho -, entendido como forma de pro- mover transformações nos ambientes e processos de trabalho, é referido unicamente na Constituição do Estado do Rio de Janeiro (5\%).

O Grupo IV, que caracteriza a garantia de direitos de cidadania, composto pelos atributos de no 14 a 20 (sete atributos), foi encontrado nas constituições de dez estados, representando $47,6 \%$ do total analisado.

Dentre os atributos que compõem esse grupo, destaca-se o de no 15 - acesso do trabalhador às informações - , presente nas constituições de oito estados (38,1\%). Seguindo-se em ordem de freqüência, vêm, respectivamente, os atributos de no 16 e 17 - participação sindical e recusa ao trabalho em ambientes de risco -, cada qual presente nas constituições de cinco es$\operatorname{tados}(23,8 \%)$.

A questão da assistência e da recuperação dos trabalhadores, aspecto dos mais relevantes para a área, é refererido nas constituições de apenas cinco estados, representando $(23,8 \%)$ do universo considerado.

O atributo apuração de responsabilidades, que propicia a abertura de processos judiciais de responsabilização civil e criminal contra a parte infratora, é uma forma extremamente eficaz de forçar as transformações na área, na medida em que o causador do dano é de fato responsabilizado, podendo-Ihe ser atribuídas sanções tanto pecuniárias como de perda da liberdade. A despeito do alcance de tal enunciado legal, somente o Estado do Ceará garantiu-o em sua constituição (5\%). Cabe, contudo, ressaltar que, independentemente desta lacuna nas demais constituições estaduais, os Códigos Civil (Negrão, 1995) e Penal (Delmanto, 1991) garantem, no Brasil, a imputação de tais responsabilidades.

Ainda neste grupo, o Estado de São Paulo foi o que mais apresentou atributos (quatro), refletindo, sem dúvida, o fato de ser o lugar onde o movimento sindical é mais organizado e atuante na área de Saúde do Trabalhador.

A intenção de se emitir um juízo de valor àquelas constituições estaduais em que a legislação pode ser considerada mais avançada, por conter não só um maior número de atributos em relação à área, como pela qualidade das citações (diretamente) referidas e, também, pela distribuição dos atributos nos quatro grupos temáticos, pretende, tão somente, estabelecer parâmetros e possibilitar correlações com o desenvolvimento atual das ações nos estados.

Desta forma, podem-se considerar os Estados mais avançados: Rio de Janeiro (12 atributos distribuídos nos quatro grupos), Amazonas (nove atributos distribuídos em três grupos), Pernambuco (nove atributos distribuídos em 
dois grupos), Bahia e São Paulo (sete atributos distribuídos em três grupos).

À exceção do Estado do Amazonas, onde não se tem notícia de ações de relevância no nível do SUS estadual, os estados assinalados, através de ações sistemáticas, vêm buscando consolidar a área de Saúde do Trabalhador no SUS.

\section{Conclusão}

O desafio de se trabal har com as intencionalidades do legislador, suas motivações e pressões sofridas no processo de criação de leis acerca de temas tão relevantes quanto os relacionados à saúde dos trabal hadores, remete à necessidade de aprofundamento do tema, envolvendo atores diversos e utilizando instrumentos mais sofisticados de pesquisa e avaliação. O fôlego deste artigo é, sem dúvida, curto, para dar conta dessa complexidade. A continuidade do trabalho já vem se dando por recortes e aproximações em outros trabalhos dos autores.

Por enquanto, cabe chamar a atenção para alguns aspectos, presentes de forma ora mais, ora menos objetiva na análise.

Por certo, um deles é o fato de a lei apresentar lacunas, aqui e acolá, relembrando que em cinco estados sequer se menciona a questão de Saúde do Trabalhador, fixando claramente o muito por fazer pela área no campo do Poder Legislativo.

Outro aspecto é a forma e a intensidade da resposta do Poder Executivo ao ditame da lei, consi derando-se que as ações de Saúde do Trabalhador são, ainda, incipientes no nível do
SUS, na maioria dos Estados da Federação, mesmo naqueles onde mais ousou o legislador, como é o caso do Amazonas. "Os desdobramentos legais para que se cel ebrem estas atribuições no âmbi to do SUS ainda estão por ser revistos" (Carvalho \& Santos, 1992).

$\mathrm{O}$ atributo mais freqüentemente assinalado nas constituições estaduais (dez citações) diz respeito às fiscalizações/inspeções dos ambientes de trabalho. Reflete, sem dúvida, a intenção de conferir ao Sistema Único de Saúde a responsabilidade de intervir nos processos de trabalho, segundo o prisma da saúde pública, como contraponto à fiscalização tradicional, exercida pelo Ministério do Trabalho. É muito provável que o legislador tenha refletido a crítica que se faz à metodologia tradicional de intervenção, cujos resultados têm sido, há muito, questionados.

A escassa referência à questão das informações acerca dos acidentes e doenças do trabaIho, historicamente confinadas à Previdência Social e utilizadas tão somente ao pagamento de benefícios, reflete a dificuldade de se mudar o enfoque para as ações preventivas. Curiosamente, em nenhuma constituição faz-se referência a esta questão.

Finalmente, registre-se que o Grupo IV Garantia de Direitos de Cidadania -, embora tenha apresentado o maior número de atributos (sete), só os teve assinalados em dez dos 21 estados. Aquela que foi chamada de constituição cidadã não conseguiu influenciar e sensibilizar o legislador estadual, no sentido de garantir na lei a conquista da cidadania por parte dos trabalhadores, nas questões da relação entre saúde e trabalho.

\section{Referências}

BRASIL, 1988. Constituição da República Federativa do Brasil. Brasília.

CARVALHO, G. I. \& SANTOS, L., 1992. Sistema Único de Saúde, Comentários à Lei Orgânica da Saúde (Lei 8.080/90 e Lei 8.141/90). São Paulo: Hucitec.

DELMANTO, C., 1991. Código Penal Brasileiro Comentado e Legi slação Complementar. Rio de Janeiro: Edição Renovar.

DIAS, E. C., 1995. A Atenção à Saúde dos Trabal hadores no Setor Saúde(SUS), no Brasil: Realidade, Fantasia ou Utopia. Tese de Doutorado, São PauIo: Departamento de Medicina Preventiva e Social da Universidade de Campinas.
MACHADO, J. M. H. \& BARCELLOS, C. S., 1993. Vigilância em saúde do trabalhador. 2ạ Conferência Estadual deSaúdedo Trabalhador. Rio de Janeiro. (mimeo.)

MENDES, R., 1986. Doutrina e Prática da Integração da Saúde Ocupacional no Setor Saúde: Contribuição para Definição de uma Política. Tese de Livre Docência, São Paulo: Faculdade de Saúde Pública, Universidade de São Paulo.

MS (Ministério da Saúde), 1990. Lei Orgânica da Saúde. Brasília: MS

MS (Ministério da Saúde), 1994. NOST - Norma Ope racional Básica de Saúde do Trabalhador no SUS. Brasília: MS. (mimeo.) 
NEGRÃO, T., 1995. Código Civil eLegislação Civil em Vigor. São Paulo: Editora Saraiva.

OLIVEIRA, L. S. B., 1994. A Intervenção do Estado nos Ambientes de Trabal ho: Origens, Evolução no Brasil e Análise Crítica da Prática da Delegacia Regi onal do Trabal ho do Rio de Janeiro na Década de 1980. Dissertação de Mestrado, Rio de Janeiro: Escola Nacional de Saúde Pública, Fundação Oswaldo Cruz.

OLIVEIRA, M. H. B. \&VASCONCELLOS, L. C. F., 1992. Política de saúde do trabalhador no Brasil: muitas questões sem respostas. Cadernos de Saúde Pública, 8:150-156.

RIBEIRO, F. S. N., 1994. Da Identidade do Pesquisado à Identidade da Pesquisa - Os Trabalhadores Brasileiros na Pesquisa Nacional sobre Saúde e Nutrição. Dissertação de Mestrado, Rio de Janeiro: Escola Nacional de Saúde Pública, Fundação Oswaldo Cruz.
TAM BELLINI, A. T., 1986. Avanços na formulação de uma política de saúde do trabalhador. I Conferência Nacional deSaúde do Trabal hador. Rio de Janeiro: Fiocruz/ENSP. (mimeo.)

VASCONCELLOS, L. C. F. \& RIBEIRO, F. S. N. Investigação epidemiológica e intervenção sanitária em saúde do trabalhador - o planejamento segundo bases operacionais. Cadernos de Saúde Pública, (no prelo)

VASCONCELLOS, L. C. F., 1994. Os Caminhos do Caminho - A Municipalização como Estratégia de Consol idação da Saúde do Trabal hador no Setor Saúde. Dissertação de Mestrado, Rio de Janeiro: Escola Nacional de Saúde Pública, Fundação Oswaldo Cruz. 